\title{
Use of State Administrative Data Sources to Study Adolescents and Young Adults with Rare Conditions
}

\author{
J. A. Royer' , J. W. Hardin², S. McDermott², L. Ouyang 3 , J. R. Mann 4, O. D. Ozturk' , and J. Bolen ${ }^{3}$ \\ 'Division of Research and Statistics, South Carolina Budget and Control Board, Columbia, SC, USA; ${ }^{2}$ Department of Epidemiology and \\ Biostatistics, University of South Carolina Arnold School of Public Health, Columbia, SC, USA; ${ }^{3}$ Centers for Disease Control and Prevention \\ National Center on Birth Defects and Developmental Disabilities, Atlanta, GA, USA; ${ }^{4}$ Department of Family and Preventive Medicine, \\ University of South Carolina School of Medicine, Columbia, SC, USA; ${ }^{5}$ Moore School of Business, Department of Economics, University of South \\ Carolina, Columbia, SC, USA.
}

BACKGROUND: Effective care of young people with rare conditions requires ongoing coordinated medical treatment as well as educational and social support services. However, information on treatment is often lacking due to limited data. South Carolina has a repository of comprehensive health and human service data with which individuals may be tracked across the data systems of multiple state agencies and organizations.

OBJECTIVE: To develop a method for studying health care of young persons with rare conditions using this repository.

METHODS: We identified individuals aged 15 to 24 years diagnosed during 2000-2010 with Fragile $\mathrm{X}$ syndrome (FXS), spina bifida (SB), or muscular dystrophy (MD) using a series of algorithms. ICD-9CM codes were used to initially identify the cohort from medical billing data. Demographics, medical care, employment, education, and socioeconomic status data were then extracted from linked administrative sources.

RESULTS: We identified 1,040 individuals with these rare conditions: 125 with FXS, 695 with SB, and 220 with MD. The vast majority of the cases (95\%) were identified in the Medicaid database. Half of the cohort was male, with a higher percentage in the FXS and MD groups. Sixty-two percent of the cohort was enrolled in the last year of high school. Over half of the cohort received support services from the state's disability and special-needs agency; $16 \%$ received food assistance. Thirty-eight percent were employed at some point during the study period. Forty-nine individuals with $\mathrm{SB}$ and 56 with MD died during the study period.

CONCLUSIONS: We used a linked statewide data system to study rare conditions. Strengths include the diversity of information, rigorous identification strategies, and access to longitudinal data. Despite limitations inherent to administrative data, we found that linked state data systems are valuable resources for investigating important public health questions on rare conditions.

KEY WORDS: adolescent health; health services research; utilization. J Gen Intern Med 29(Suppl 3):S732-8

DOI: $10.1007 / \mathrm{s} 11606-014-2925-7$

(C) Society of General Internal Medicine 2014

Published online July 17, 2014

\section{BACKGROUND}

Collectively, rare conditions affect millions of people worldwide, often causing severe physical and mental impairments and reducing quality of life. ${ }^{1}$ These disorders are challenging for the individual, family, and society, leading to considerable morbidity and mortality, disproportionate use of health care services, and significant social, emotional, and financial difficulties. ${ }^{2,3}$ Better information is needed to describe the epidemiology and the secondary health conditions associated with these disorders, monitor progress of public health interventions, develop screening strategies for the detection of new cases, inform policies to improve healthcare, and address differences or disparities in the impact on the population. ${ }^{4}$ There is currently no system or integrated approach to identify and describe persons affected by these conditions across their life-span. ${ }^{4}$ Population-based registries and surveillance systems for rare conditions require infrastructure, constant tracking, and a significant investment of resources. ${ }^{5}$ Linked populationbased administrative data are a powerful, low-cost tool for public health research. ${ }^{6}$

We used linked state-level administrative data from South Carolina, a moderate-sized state (population 4.7 million) that is $64.0 \%$ non-Hispanic White, $28.0 \%$ non-Hispanic Black or African American, $5.3 \%$ of Hispanic/Latino ethnicity, and $3.6 \%$ other race/ethnicity. ${ }^{7}$ The South Carolina Budget and Control Board, Division of Research and Statistics (DRS), is a central repository for health and human service data. Data housed at DRS and utilized for this project originated from Medicaid, the State Health Plan (SHP), the Uniform-billing Hospital Discharge Dataset (HDD), the Department of Disabilities and Special Needs (DDSN), the Department of Social Services (DSS), the State Department of Education (SDE), the South Carolina Department of Health and Environmental Control Vital records, and the Department of Unemployment and Workforce. See Table 1 for a description of the data sources and variables analyzed.

We focused on adolescent and young-adult years, because for persons with rare conditions, this is an important transitional time from pediatric to adult health care and from living as dependents to a more independent lifestyle. We chose Fragile X syndrome (FXS), spina bifida (SB), and muscular dystrophy (MD) as examples of rare conditions. 
Table 1. Databases Included in this Project: Available Through the South Carolina Budget and Control Board, Division of Research and Statistics (DRS)

\begin{tabular}{lll}
\hline \hline Data Source & Data Description & Variables Analyzed \\
\hline Medicaid, State Health Plan (SHP) \& & Medical claims and billing data. In fiscal year & Demographic variables such as age, sex, \\
Uniform Billing Hospital Discharge & 2011, Medicaid and SHP covered approximately & and race (if available). Encounter-level \\
Database (HDD) & $\begin{array}{l}\text { 1,300,000 state residents. SHP covers } \\
\text { inproximately 435,000 people. Both data sets }\end{array}$ & variables such as diagnosis and procedure \\
& include facility and professional claims for & codes, and total number of prescriptions.
\end{tabular}
include facility and professional claims for covered individuals. HDD include all-payer inpatient, emergency department, outpatient imaging, and outpatient surgery encounters and captures nearly $100 \%$ of patients seen. Data for Medicaid dates back to 1990, 1985 for HDD inpatient, 1995 for HDD outpatient, and 1996 for SHP. The HDD is $99.9 \%$ complete and $99.5 \%$ accurate by state mandate.*

Department of Disabilities and Special Needs (DDSN)

Department of Education (SDE)

Department of Social Services (DSS)

South Carolina Department of Health and Environmental Control (DHEC)

Department of Unemployment and Workforce (DEW)
DDSN's mission is to serve individuals with intellectual disability and related disabilities, autism, and head and spinal cord injury in the least restrictive environment by providing support services to these individuals and their families. In fiscal year 2011-2012, more than 32,000 individuals received such services; data include information about recipient characteristics as well as residential, day services, and other support services.

The SDE data file contains data regarding all public education school students. Files represent a "snapshot" of students near the beginning of the school year, including special education or other placement, free and assisted lunch, and grade completed.

In 2012, the Supplemental Nutrition Assistance Program (SNAP - formerly Food Stamps) serves over 400,000 households and 800,000 people, using the federal poverty guideline for eligibility.

The Office of Vital Statistics at DHEC maintains records for births, deaths, fetal deaths, marriages, and divorces occurring in the state. The birth/ death data was utilized for this project.

DEW shares wage, claim, and employment information with DRS in order to: 1) meet the research needs of employers and prospective employers, 2) provide information to show the effectiveness of programs, and 3) provide information to be used to conduct research using education, training, employment, and health outcomes. Only aggregate information is available.
Employment status, residential setting, skills acquired (activities of daily living), services received, and Fragile X Genetic Testing Registry.

Last grade level enrolled and academic assistance received.

Indicator if receiving assistance as proxy for socio-economic status.

Birth certificate myelomeningocele/ meningocele (spina bifida) indicator, indicator if person died, and cause of death.

Average length employed in years and average wage by year.

\footnotetext{
* DRS checks hospital discharge data for completeness and accuracy and developed a feedback mechanism as a report card to provide these measures to each hospital on a monthly basis. All other data sources meet completeness requirements as designated by the originating agency. Because all sources share common quality limitations inherent to administrative data, they all have missing and misclassified data except for edited hospital discharge data
}

FXS, a neurodevelopmental disorder produced by a mutation in the Fragile X Mental Retardation 1 gene on the $\mathrm{X}$ chromosome, is the leading inherited cause of intellectual disability. ${ }^{8}$ Impairment can range from learning difficulties to intellectual disabilities and autism or "autisticlike" behaviors. Few studies have described the adult experience of persons with FXS. ${ }^{9}$

$\mathrm{SB}$ is a birth defect that occurs when the neural tube fails to close properly during fetal development. The life experience of people with SB is related to the level of the neural tube defect and the presence or absence of hydrocephalus. Studies conducted over the past 25 years have shown that although survival and quality of life for those with SB have improved, young adults with SB have a lower rate of independence, employment, and educational attainment. ${ }^{10-16}$

Muscular dystrophies are a group of genetic conditions causing progressive skeletal muscle weakness. The severity, age of onset, rate of progression, complications, and prognosis of this group of diseases vary greatly. ${ }^{17}$ Duchenne muscular dystrophy is the most common form among children, with an average age at diagnosis of 5 years, loss of ambulation between 7 and 13 years, and death in 
early adulthood. ${ }^{17}$ Improved treatment has extended the life expectancy of these individuals, increasing the use of adult services. ${ }^{18,19}$

Here we present our methods to study adolescents and young adults with these three rare conditions. We discuss identification in the general population, the use of novel data sources, and provide examples of research questions that can be answered with these data. Finally, we discuss the strengths and limitations of our approach.

\section{METHODS}

Through a series of statutes and agreements, agencies and organizations entrust data to DRS while retaining access control at all times. DRS developed a series of algorithms using source-specific personal identifiers to create a global unique identifier (UID). Personal identifiers include (but are not limited to) social security number, name, date of birth, race, and gender. The data are cleaned and standardized before the generation of a UID, which without ever being associated with any personal identifiers, is used on all subsequent episodes of services, regardless of data source or service provider. Using the UID in lieu of personal identifiers enables views of data across multiple providers while protecting confidentiality. Data usage approvals were obtained from participating organizations from which the data originated. Data limitations and quality measures are discussed in Table 1. All data linkages were performed at DRS. Non-DRS investigators were provided a de-identified data set or aggregate results, depending on data usage approval.

\section{Identification of Persons with FXS, SB, and MD}

All persons aged 15 to 24 years with an ICD-9-CM primary or secondary diagnosis code for FXS, SB, or MD during the study period 2000-2010 were identified from Medicaid, HDD, and SHP claims data. Additionally, we identified cases of intellectual disability, autism spectrum disorder, paraplegia, wheelchair dependence, and progressive muscular atrophy to determine whether a diagnosis of FXS, SB, or MD had been made prior to age 15 years. See Table 2 for a list of specific and potential inclusion diagnosis codes.

Confirmatory variables including FXS genetic testing results from the DDSN Fragile X Registry and myelomeningocele/ meningocele indicator from birth certificate records were used to further identify the cohort. If confirmatory data were not available, then at least two diagnosis codes were required for the case to remain in the final cohort. If other chronic condition codes were found in the record and were coded at a frequency greater than the condition of interest, the case was excluded. The following conditions were considered in this category: 1) cerebral palsy for $\mathrm{SB}$ and $\mathrm{MD}$ and 2) multiple sclerosis for MD. Additionally, all persons had to be enrolled in either Medicaid or SHP for at least one full year when 15 to 24 years of age. Numbers of exclusions per criterion are shown in Table 3. The target population was residents with one of the rare conditions. We investigated the types and frequencies of healthcare needs of these residents compared to healthy controls and between conditions. The purpose was to highlight the transition from adolescence to adulthood in this cohort of young people with rare conditions.

\section{Medical Encounters and Vital Records}

Once cohorts for each condition were established, all medical claims and outpatient pharmacy encounters (regardless of diagnosis codes) from Medicaid and SHP were selected for the study period using each UID.

Emergency department visits were indicated for inpatient and outpatient encounters if a patient was admitted through the emergency department. Surgical encounters were identified by 1) flagging non-zero operating-room charges and 2) searching ICD-9-CM procedure codes for valid operatingroom procedures (Healthcare Common Procedure Coding and Current Procedural Terminology codes were converted to ICD-9CM codes using Truven Health Analytics software).

Claims for professional services provided within a facility were considered to be the same encounter of care as the facility encounter. This allows for facility and professional paid amounts to be averaged per encounter along with other variables of interest (e.g., number of procedures performed or number of different specialty types). Non-facility professional components were assigned an encounter type based on rendering provider type, location, and specialty. If more than one rendering specialty was noted, the specialty with the highest paid amount was assigned. Encounter types included, but were not limited to, inpatient, emergency department, outpatient surgery, primary care, specialty care, therapy, home health, durable medical equipment, and pharmacy. DRS staff conducted all encounter assignments. When Medicaid or the SHP was not the only payer, it is possible that professional and/or facility components were paid entirely by another source and are missing from the analyses.

Death certificate data for 2000-2011 were extracted using each case's UID. Age at death was calculated, and underlying cause and comorbid causes of death were selected for additional analysis.

\section{Education, Work History, and Social Services}

SDE annually provides a file that represents a "snapshot" of students at or near the beginning of the school year ${ }^{20}$ and includes current grade enrolled. This information is available through the twelfth grade; however, completion of high school is unknown. Students receiving special education services were identified through the Education Finance Act, 
Table 2. International Classification of Diseases, Ninth Revision, Clinical Modification (ICD-9-CM) Diagnosis Codes Utilized

\begin{tabular}{|c|c|c|}
\hline Condition & Specific Condition Codes & Possible Inclusion Codes \\
\hline Fragile X Syndrome & 759.83 Fragile X Syndrome & $\begin{array}{l}317 \text { - } 319 \text { Intellectual Disability } \\
299 \text { Pervasive Developmental Disorder }\end{array}$ \\
\hline Spina Bifida & $\begin{array}{l}\text { 741.0 Spina Bifida with Hydrocephalus } \\
\text { 741.9 Spina Bifida without Hydrocephalus }\end{array}$ & $\begin{array}{l}331.3 \text { - } 331.5 \text { Communicating, } \\
\text { Obstructive and Idiopathic Normal Pressure } \\
\text { Hydrocephalus } \\
\text { 344.1 Paraplegia } \\
\text { V46.3 Wheelchair Dependence }\end{array}$ \\
\hline Muscular Dystrophy & $\begin{array}{l}\text { 359.0 Congenital Hereditary Muscular Dystrophy } \\
\text { 359.1 Hereditary Progressive Muscular Dystrophy } \\
\text { 359.21 Myotonic Muscular Dystrophy }\end{array}$ & $\begin{array}{l}\text { 335.21 Progressive Muscular Atrophy } \\
\text { V46.3 Wheelchair Dependence }\end{array}$ \\
\hline
\end{tabular}

which contains up to ten codes. A review of all available records determined receipt of special education services, type of educational placement, and setting.

DDSN's mission is "to serve individuals with intellectual disability and related disabilities, autism, head and spinal cord injury in the least restrictive environment possible by providing support services to these individuals and their families." ${ }^{21}$ DDSN data housed at DRS include: 1) a residential setting file, 2) a service file, and 3) a skills file. DSS Supplemental Nutrition Assistance Program (SNAP - formerly Food Stamps) currently serves over 400,000 households and 800,000 people within the state. ${ }^{22}$ The time of receipt of SNAP benefits was calculated for each UID. Data from the Department of Unemployment and
Workforce for each case from 2005-2012 were summarized and aggregate results provided to researchers. Data included number of years employed and annual salary.

\section{RESULTS}

\section{Medical Encounters and Vital Records}

In the final cohort, 125 persons (71 \% male) with FXS, 695 persons ( $41 \%$ male) with SB, and 220 persons (69\% male) with MD were identified. Of these 1,040 cases, 373 (35.9\%) were identified solely from the Medicaid database, 610 (58.6\%) from Medicaid and HDD and/or SHP, and 57

Table 3. Number of Potential Cases Identified, Exclusion Criteria, and Number Excluded

\begin{tabular}{|c|c|c|c|c|}
\hline & Definitions and Exclusion Rules & Fragile X Syndrome & Muscular Dystrophy & Spina Bifida \\
\hline 1 & $\begin{array}{l}\text { Initial Data Pull } \\
\text { \# } 15 \text { - to } 24 \text {-year-olds with specific condition ICD-9-CM diagnosis } \\
\text { code during study period* }\end{array}$ & 104 & $<364^{\pi}$ & 1,013 \\
\hline 2 & $\begin{array}{l}\text { \# 15- to 24-year-olds with potential ICD-9-CM diagnosis code } \\
\text { during study period* }\end{array}$ & 14,371 & 102 & 1,837 \\
\hline \multirow[t]{3}{*}{3} & $\begin{array}{l}\text { \# Identified from row } 2 \text { with at least one occurrence of specific } \\
\text { condition code }\end{array}$ & 109 & $<10^{\pi}$ & 116 \\
\hline & $\begin{array}{l}\text { Total with at least one occurrence with specific condition code } \\
(\text { sum } 1 \& 3)\end{array}$ & 213 & 364 & 1,129 \\
\hline & $\begin{array}{l}\text { Exclusions } \\
\text { Only one specific condition code found }\end{array}$ & 78 & 70 & 179 \\
\hline 5 & $\begin{array}{l}\text { Other chronic conditions identified, case excluded if other chronic } \\
\text { condition diagnosed more often than condition of interest } \mathrm{s}^{\S}\end{array}$ & $\mathrm{n} / \mathrm{a}$ & 28 & 28 \\
\hline \multirow[t]{3}{*}{6} & Did not meet eligibility requirements or was not state resident $\|$ & 10 & 46 & 227 \\
\hline & Total number excluded (sum 4-6) & 88 & 144 & 434 \\
\hline & Final Cohort (Initial Data Pull Total - Number Excluded) & 125 & 220 & 695 \\
\hline
\end{tabular}

*study period 2000-2010, see Table 1 for specific and potential inclusion condition codes; all three health databases were searched for codes, and cases were unduplicated using DRS unique identifier

${ }^{*}$ considered diagnoses from encounters prior to study period and outside of age range

exceptions to one-code exclusions rule include 1) genetic confirmation of FXS and 2) myelomeningocele/ meningocele noted on birth certificate for $S B$, and 3) hydrocephalus/shunt code for $S B$

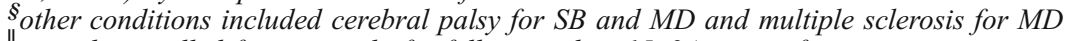

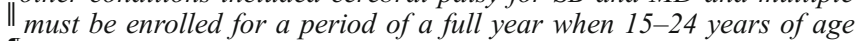

${ }^{\top}$ cells containing numbers $\leq 10$ are masked to protect patient confidentiality; because line three is a total count, line one is also masked 
Table 4. Annual Mean Number of Visits (Standard Deviation) By Condition and Encounter Type

\begin{tabular}{llll}
\hline \hline & Fragile X Syndrome & Spina Bifida & Muscular Dystrophy \\
\hline Encounter Type & Mean Number of Visits (Standard Deviation) & & \\
Total & $48.1 \pm 68.1$ & $58.2 \pm 95.3$ & $81.0 \pm 118.1$ \\
Inpatient & $0.2 \pm 0.5$ & $0.4 \pm 0.7$ & $0.3 \pm 0.7$ \\
Emergency Department & $0.4 \pm 0.7$ & $1.0 \pm 1.8$ & $0.6 \pm 0.9$ \\
Primary Care & $2.5 \pm 2.3$ & $3.7 \pm 4.9$ & $3.4 \pm 4.2$ \\
Specialty Care & $1.3 \pm 2.5$ & $1.9 \pm 3.1$ & $2.0 \pm 2.7$ \\
Therapy & $19.3 \pm 41.3$ & $12.2 \pm 38.1$ & $11.5 \pm 36.6$ \\
Home Health & $9.7 \pm 38.1$ & $24.6 \pm 68.0$ & $48.6 \pm 95.1$ \\
Durable Medical Equipment & $1.9 \pm 13.0$ & $9.4 \pm 9.0$ & $5.6 \pm 10.8$ \\
All Other Encounter Types & $12.9 \pm 25.4$ & $16.0 \pm 16.8$ & $9.0 \pm 15.9$ \\
Pharmacy & $17.7 \pm 19.7$ & $18.0 \pm 18.1$ \\
\hline
\end{tabular}

(5.5\%) from HDD and/or SHP but not Medicaid. Therefore, $94.5 \%$ of the cohort was found at some point in the Medicaid database. The mean and standard deviation of visits by encounter type for each condition are shown in Table 4.

Of the 220 individuals with MD, 56 (25\%) died during this period. The median age of death was 22 years; most died of cardiac complications with G71 (ICD-10 code for MD) listed $64 \%$ of the time as the underlying cause of death. Of the 695 individuals with SB, 49 (7.1\%) died during this period. Their median age of death was 24 years, and the most frequent cause of death was kidney failure or other renal complication. Few FXS cases were linked to death certificate data.

\section{Education, Work History, and Social Services}

Of the 1,040 individuals in the cohort, 970 (93\%) could be linked to SDE data, of whom 604 (62\%) had enrolled in the twelfth grade. The percentages were similar among the three rare-condition groups for those that were linked $(\mathrm{FXS}=64 \%$, $\mathrm{MD}=65 \%$, and $\mathrm{SB}=61 \%$ ). Seventy-one percent of the cohort required special education assistance, with a considerably higher percentage requiring assistance in the FXS group (90\%) than the other two groups $(\mathrm{MD}=65 \%$ and $\mathrm{SB}=63 \%)$. Five hundred and fifty-seven $(54 \%)$ cases were linked to DDSN data. The percentage linked was higher for the FXS group (80\%) than the other two groups (MD=54\% and $\mathrm{SB}=49 \%)$. During the study period, 169 individuals received food purchasing assistance. The percentage was lowest for MD (10\%), highest for SB (18\%), and FXS was $17 \%$. The percentage of persons working was highest in the SB group (43\%) and lowest in the FXS group (25\%). Thirty percent of those in the MD group were employed at some point during this time period.

\section{DISCUSSION}

To better understand determinants of health and well-being among South Carolinians with rare conditions, a linked data set was constructed from health, education, and social services sources. The purpose of this manuscript is to describe the data sources, case ascertainment strategies, variables, and examples of research questions that may be answered using this data set. This extensive network of linkable data is unique to South Carolina and has required careful negotiation, attention to privacy concerns, and a commitment by stakeholders over decades; however, other states have embarked on similar projects to answer questions about the health of their citizens (e.g., ${ }^{23-24}$ ). Three key principles have served DRS well over the years: 1) the data housed in the warehouse are never owned by DRS; permission to use the data must be granted by the data owner for each new request; 2) a UID is used in lieu of personal identifiers; and 3) the DRS is politically and policy neutral; it is a service entity for researchers, other state agencies, and private citizens.

Like anyone else with a major health-related condition, persons with rare conditions require frequent hospitalizations, emergency department visits, therapeutic interventions, durable medical equipment, and home health services. Thus, hospital discharge and medical claims data are useful for case identification. The most common case identification strategy for identifying cohorts using ICD-9-CM codes reported in the literature for $\mathrm{FXS}, \mathrm{SB}$, or $\mathrm{MD}^{25-28}$ is for inclusion criteria to be limited to at least one diagnosis. While there have been no specific reviews of ICD-9 code accuracy regarding FXS, SB, or MD in the United States, broader reviews of the literature reveal that unintentional coder errors caused by the limits of the clinician's knowledge and experience with the condition, misinterpreted information from the clinical record, and data entry mistakes lead to inaccuracy in ICD coding. ${ }^{29-31}$ To control for miscoding, our inclusion criteria required two or more diagnoses of FXS, SB, or MD. The specification of at least two occurrences of a diagnosis was used in a Canadian study, which linked two surveillance systems; for spina bifida, they found an agreement rate of $64.1 \%{ }^{32}$ Higher positive predictive values for identifying cases of amyotrophic lateral sclerosis for the National Amyotrophic Lateral Sclerosis Registry were obtained when criteria for case identification included multiple occurrences of the diagnosis code, searching for diagnosis codes in multiple years, and linking to additional sources for case confirmation. ${ }^{33,34}$ 


\section{Examples of Research Questions that Can Be Answered Using the Linked Administrative Data System}

This linked data system is useful for answering research questions related to health care utilization and social outcomes for people with the specified conditions. The data are currently being analyzed by our research team to: 1) Investigate the characteristics of people 15-19 and 20-24 years old with FXS, $\mathrm{SB}$, or $\mathrm{MD}$, including their demographics, socioeconomic status (SES), educational attainment, employment experiences, and social services received. 2) Compare rates of hospitalizations and emergency department visits for all and select causes, including ambulatory care sensitive conditions among persons with $\mathrm{FXS}, \mathrm{MD}$, or $\mathrm{SB}$ to a comparison group without any of these conditions. ${ }^{35}$ 3) Examine the role of SES in the pattern of health care use (primary regular care vs. hospitalizations and emergency room visits) among persons with MD covered by Medicaid. ${ }^{36} 4$ ) Identify conditions cooccurring with FXS, including attention deficit disorder, epilepsy, autism spectrum disorder, and intellectual disability. ${ }^{37}$ Additional studies are under development.

\section{Strengths and Limitations of Using State-Linked Data System to Study Rare Conditions}

Calculated prevalence rates per 10,000 persons for individual study years (2000, 2005, and 2010) using case identification algorithms defined in the methods prior to eligibility requirement exclusions range from 1.9 to 3.3 for $\mathrm{SB}, 1.1$ to 1.2 for $\mathrm{MD}$, and 0.3 to 0.5 for FXS. FXS rates are slightly lower than reported prevalence rates, ${ }^{38-40}$ whereas SB and MD rates are similar to reported prevalence rates. ${ }^{41-43}$

The strengths of this method include the diverse types of information available, including data from medical claims, hospital discharges, education, social, and disability services. Using merged data from multiple sources, we identified persons with one of three rare conditions based on all years of medical claims data available. We used sources such as birth certificates and genetic clinic testing for case confirmation. We have multiple observations on medical encounters, education, and social services for the same person. Linking events across disparate sources and over time enables the study of life patterns in health, health care, and other domains. However, one limitation of administrative data is a lack of individual-level measures of SES. We constructed correlates of SES including food stamp receipt, high school completion, and race; these measures are often related to health care use patterns. There is variation in SES for those covered by Medicaid in South Carolina because of the Katie Beckett rule of the Tax Equity and Fiscal Responsibility Act of 1982 (Pub.L. 97-248), which ensures that children with severe disabilities are covered regardless of parents' income. Likewise, adults with substantial disability qualify for Medicaid regardless of their parents' income, if their own income and assets are below poverty levels. Along with 11 other states, South Carolina extends Medicaid coverage to people with disabilities who work. South Carolina also provides Medicaid to working people with a disability who earn below $250 \%$ of the federal poverty level through Section 4733 of the Balanced Budget Act of 1997. Thus, for children and some adults with rare conditions in South Carolina, enrollment in Medicaid is not synonymous with poverty.

We recognize a number of limitations. Due to the nature of administrative data, we have information only on persons who interacted with the state systems. Even for those for whom data are available, we do not necessarily capture all information; for example, some individuals may be dually insured in addition to Medicaid or the State Health Plan, and we have no access to billing to other payers (unless evidence of those charges was present in hospital discharge data). Second, administrative data were not collected for research purposes and do not always contain a sufficient level of detail. Finally, medical claims data are not linked with medical records or clinical data. Absent associated registries, we cannot validate our identification strategy and confirm all of the rare conditions.

Despite these limitations, linked state data systems are valuable and relatively inexpensive data sources with which to study rare conditions. We learned about care patterns, disparities in care, care expenditures, comorbid conditions, and educational and employment outcomes during transitions from adolescence to young adulthood for persons with rare conditions. Research using linked administrative databases yields important public health insights for the population with rare disorders. To construct a similar data system absent a centralized service entity like DRS, interested researchers outside of South Carolina might need to contact individual entities for data, and then manage the linking of data across those entities.

\begin{abstract}
Acknowledgements: This work was supported by Grant No. 5U01DD000776-03 (CFDA No. 93.283) from the U.S. Department of Health and Human Services Centers for Disease Control and Prevention. The findings and conclusions in this report are those of the authors and do not necessarily represent the views of the Centers for Disease Control and Prevention, the South Carolina Budget and Control Board Division of Research and Statistics, the South Carolina Department of Health and Human Services, the South Carolina Public Employee Benefits Authority, the South Carolina Department of Education, or the South Carolina Department of Social Services.
\end{abstract}

Conflict of Interest: The authors declare that they do not have a conflict of interest.

Corresponding Author: J. A. Royer, Division of Research and StatisticsSouth Carolina Budget and Control Board, 1919 Blanding Street, Columbia, SC 29201, USA (e-mail: Julie.Royer@ors.sc.gov). 


\section{REFERENCES}

1. Eurordis. The Voice of Rare Disease Patients in Europe. Available at: http://www.eurordis.org Accessed July 2, 2013

2. Ouyang L, Grosse SD, Fox MH, Bolen J. A national profile of health care and family impacts of children with muscular dystrophy and special health care needs in the United States. J Child Neurol. 2012;5:569-76.

3. Ouyang L, Grosse S, Raspa M, Bailey D. Employment impact and financial burden for families of children with fragile $\mathrm{X}$ syndrome: findings from the National Fragile X Survey. J Intellect Disabil Res. 2010:54(10):918-28.

4. Groft SC, De la Paz Posada M. Rare diseases-avoiding misperceptions and establishing realities: the need for reliable epidemiological data. In: Groft SC, De la Paz Posada M, eds. Rare Diseases Epidemiology. Netherlands: Springer; 2010:3-14.

5. Miller LA, Romitti PA, Cunniff C, Druschel C, Mathews KD, Meaney FJ, Matthews D, Kantamneni J, Feng ZF, Zemblidge N, Miller TM, Andrews J, Fox D, Ciafaloni E, Pandya S, Montgomery A, Kenneson A. The muscular Dystrophy Surveillance Tracking and Research Network (MD STARnet): surveillance methodology. Birth Defects Res A Clin Mol Teratol. 2006;76(11):793-7.

6. Jutte DP, Roos LL, Brownell MD. Administrative record linkage as a tool for public health research. Annu Rev Public Health. 2011;32:91-108.

7. U.S. Census Bureau. South Carolina Quick Facts. Available at: http:// quickfacts.census.gov/qfd/index.html Accessed July 2, 2013

8. Crawford DC, Acuna JM, Sherman SL. FMR1 and the fragile $X$ syndrome: human genome epidemiology review. Genet Med. 2001;3(5):359-71.

9. Hartley SL, Seltzer MM, Raspa M, Olmstead M, Bishop E, Bailey DB. Exploring the adult life of men and women with fragile $\mathrm{X}$ syndrome: results from a national survey. Am $J$ Intellect Dev Disabil. 2011;116(1):16-35.

10. Bowman RM, McLone DG, Grant JA, Tomita T, Ito JA. Spina bifida outcome: a 25 year prospective. Pediatr Neurosurg. 2001;34(3):114-20.

11. Oakeshott P, Hunt GM. Long-term outcome in open spina bifida. $\mathrm{Br} \mathrm{J}$ Gen Pract. 2003;53(493):632-6.

12. Okumura MJ, Campbell AD, Nasr SZ, Davis MM. Inpatient health care use among adult survivors of chronic childhood illnesses in the United States. Arch Pediatr Adolesc Med. 2006;160(10): 1054-60.

13. Barf HA, Post MW, Verhoef M, Jennekens-Schinkel A, Gooskens RH, Prevo AJ. Restrictions in social participation of young adults with spina bifida. Disabil Rehabil. 2009;31(11):921-7.

14. Liptak GS, Kennedy JA, Dosa NP. Youth with spina bifida and transitions: health and social participation in a nationally represented sample. J Pediatr. 2010;157(4):584-8,588. el. Epub 2010 May 20.

15. Verhoef M, Barf HA, Vroege JA, Post MW, van Asbeck FW, Gooskens RH, Prevo AJ. The ASPINE study: preliminary results on sex education, relationships and sexual functioning of Dutch adolescents with spina bifida. Eur J Pediatr Surg. 2000;10(Suppl 1):53-4.

16. Sawyer SM, Macnee S. Transition to adult health care for adolescents with spina bifida: research issues. Dev Disabil Res Rev. 2010;16(1):60-5.

17. Mercuri E, Muntoni F. Muscular dystrophies. Lancet. 2013;381(9869):845-60.

18. Abbott D, Carpenter J, Bushby K. Transition to adulthood for young men with Duchenne muscular dystrophy: research from the UK. Neuromuscul Disord. 2012:22(5):445-6. Epub 2012 Mar 17.

19. Rahbek J, Werge B, Madsen A, Marquardt J, Steffensen BF, Jeppesen J. Adult life with Duchenne muscular dystrophy: observations among an emerging and unforeseen patient population. Pediatr Rehabil. 2005;8(1): 17-28.

20. South Carolina Department of Education. 2012-2013 Funding Manual: pages 6-7. Available at: http://ed.sc.gov/agency/cfo/finance/Fiscal-Systems/documents/2012-2013FundingManual.pdf Accessed July 2, 2013

21. South Carolina Department of Disabilities and Special Needs. Available at: ddsn.sc.gov Accessed July 2, 2013

22. South Carolina Department of Social Services. Available at dss.sc.gov Accessed July 2, 2013

23. Hall ES, Goyal NK, Ammerman RT, Miller MM, Jones DE, Short JA, Van Ginkel JB. Development of a linked perinatal data resource from state administrative and community-based program data. Matern Child Health J. 2014;18(1):316-325.

24. Needell B, Cuccaro-Alamin S, Brookhart A, Jackman W, Shlonsky A. Youth emancipating from foster care in California: Findings using linked administrative data. Center for Social Services Research. Berkeley: University of California; 2002:27-29.

25. Sacco P, Capkun-Niggli G, Zhang $\mathbf{X}$. Jose R; The economic burden of fragile $\mathrm{x}$ syndrome: Healthcare resource utilization in the United States. Am Health Drug Benefits; 2013;6(2):73-83.

26. Dicianno BE. Wilson R; Hospitalizaitons of adults with spina bifida and congenital spinal cord anomalies. Arch Phys Med Rehabil. 2010;91:529-35.

27. Meyer RE, Siega-Riz AM. Sociodemographic patterns in spina bifida birth prevalence trends: North Carolina 1995-1999. Centers for Disease Control: Morbidity and Mortality Weekly Report. 2002;51(RR13):12-15.

28. Ireys HT, Anderson G, Han C, Neff J. Cost of care for Medicaid-enrolled children with selected disabilities US Dept of Health \& Human Services Office of Disability, Aging and Long-Term Care Policy. 1996; Available at http://aspe.hhs.gov/daltcp/reports/carcstes.pdf.

29. Peabody JW, Luck J, Sharad J, Bertenthal D, Glassman P. Assessing the accuracy of administrative data in health information systems. Med Care. 2004;11:1066-70.

30. O'Malley KJ, Cook KF, Price MD, Raiford Wildes K, Hurdle JF, Ashton CM. Measuring diagnoses: ICD code accuracy. Health Serv Res. 2005;40(5Pt 2): 1620-1639.

31. Fiske CT, Griffin MR, Mitchel E, Sterling TR. Grijalva CG; Accuracy of pharmacy and coded-diagnosis information in identifying tuberculosis in patients with rheumatoid arthritis. Pharmacoepidemiology and Drug Safety: 2012:21(6):666-669.

32. Wen SW, Rouleau J, Lowry RB, Kinakin B, Anderson-Redick S, Sibbald B. Turner T; Congenital anomalies ascertained by two record systems run in parallel in the Canadian province of Alberta. Canadian Journal of Public Health; 2000;91(3): 193-196.

33. Kaye WE, Sanchez M, Wu J. Feasibility of creating a National ALS Registry using administrative data in the United States. Amyotrophic Lateral Sclerosis and Frontotemporal Degeneraton, 2014; Early Online

34. Stickler DE, Royer JA, Hardin JW. Validity of hospital discharge data for identifying cases of amyotrophic lateral sclerosis. Muscle Nerve. 2011;44(5):814-816.

35. McDermott S, Hardin JW, Royer JA, Mann JR, Tong, X, Ozturk OD, Ouyang L. Emergency Department Visits and Inpatient Hospitalizations for Adolescents and Young Adults with Fragile X Syndrome. Am. J. Intellect. Dev. Disabil. 2014, In press.

36. Ozturk OD, McDermott S, Mann JR, Hardin JW, Royer J, Ouyang L. Disparities in Health Care Utilization by Race among Teenagers and Young Adults with Muscular Dystrophy: Role of Socioeconomic Status. Manuscript under review, 2014

37. Tong X, McDermott S, Mann JR, Royer JR, Hardin JW, Ozturk O, Ouyang L. Co-morbid Conditions Associated with Adolescents and Young Adults with Fragile X Syndrome. Manuscript under review, 2014.

38. Coffee B, Keith K, Albizua I, Malone T, Mowrey J, Sherman SL, Warren ST. Incidence of Fragile X Syndrome by Newborn Screening for Methylated FMR1 DNA. Am J Hum Genet. 2009;85(4):503-514. doi: 10.1016/j.ajhg.2009.09.007.

39. Tarleton JC, Saul RA. Molecular Genetic Advances in Fragile XSyndrome. J Pediatr. 1993;122(2):169-185. doi:10.1016/S00223476(06)80110-1.

40. Turner G, Webb T, Wake S, Robinson H. Prevalence of fragile $\mathrm{X}$ syndrome. Am J Med Genet. 1996;64(1):196-197.

41. Parker SE, Mai CT, Canfield MA, Rickard R, Wang Y, Meyer RE, Anderson P, Mason CA, Collins JS, Kirby RS, Correa A. National Birth Defects Prevention Network. Updated National Birth Prevalence estimates for selected birth defects in the United States, 2004-2006. Birth Defects Res A Clin Mol Teratol. 2010;88(12):1008-1016.

42. Shin M, Besser LM, Siffel C, Kucik JE, Shaw GM, Lu C, Correa A, Congenital Anomaly Multistate Prevalence and Survival Collaborative. Prevalence of Spina Bifida Among Children and Adolescents in 10 Regions in the United States. Pediatrics. 2010;126(2):274-79.

43. Centers for Disease Control and Prevention. Prevalence of Duchenne/Becker muscular dystrophy among males aged 5-24 years four states, 2007. MMWR Morb Mortal Wkly Rep. Oct 16. 2009;58(40): 1119-1122 